Vol. 21 (2017), pp. 44-65

ISSNe: 2530-6324 || ISSN: 1138-039X

DOI: https://doi.org/10.17979/afdudc.2017.21.0.3271

\title{
DOCTRINA LABORAL DEL TRIBUNAL DE JUSTICIA DE LA UNIÓN EUROPEA Y SU PROYECCIÓN EN ESPAÑA
}

\author{
LUIS FERNANDO DE CASTRO MEJUTO \\ Magistrado Especialista de la Sala de lo Social \\ del Tribunal Superior de Justicia de Galicia \\ Doctor en Derecho \\ Profesor asociado de la UDC
}

Resumen: La jurisprudencia del Tribunal de Justicia de la Unión Europea tiene una importancia vital en el desarrollo de las instituciones de nuestro derecho laboral y su interpretación conforme al derecho comunitario, haciendo imprescindible su estudio y actualización constante. A través de este artículo científico se pretende poner en valor una serie de resoluciones dictadas en el último año y que han tenido una trascendencia enorme, poniendo en jaque alguna de las instituciones más arraigadas de nuestro derecho laboral, como lo es la equiparación a efectos de su indemnización de los trabajadores interinos, cuando se produce la cobertura de su plaza; o la aproximación -bajo determinadas circunstancias- de los despidos de trabajadores de baja laboral a la nulidad, cuando lo tradicional era considerarlos improcedentes.

Palabras clave: Jurisprudencia ; tribunales europeos ; derechos laborales; discriminación

\begin{abstract}
The jurisprudence of the Court of Justice of the European Union has a vital importance in the development of the institutions of our labour law and its interpretation in conformity with Community law, making essential study and constant updating. Through this scientific article is intended to highlight some judgments in the last year and who have had a significance of huge, putting in check institutions more rooted of our labor law, such as the comparability for the purposes of its compensation for the temporary workers, when coverage of the slot; or the approach - under certain circumstances - of the dismissals of workers from sick leave to the nullity, when tradition was to consider them unfair.
\end{abstract}

Keywords: Jurisprudence; European Courts; labour Law; discrimination 
SUMARIO: I. APROXIMACIÓN AL TEMA. II. CASOS RECIENTES DEL TRIBUNAL DE JUSTICIA DE LA UNIÓN EUROPEA SOBRE DETERMINADOS TEMAS CON DIRECTA INCIDENCIA EN ESPAÑA: 1. El cese de trabajadores temporales de la Administración Pública; 2. El despido durante la incapacidad temporal; 3. La discriminación por razón de edad en el acceso a determinadas profesiones; 4. El cálculo de los umbrales de los despidos colectivos; 5. La maternidad; 6. El uso de velo islámico en el lugar de trabajo; y 7. El acceso a un puesto de trabajo sólo para solicitar una indemnización por discriminación. III. CONCLUSIONES

\section{APROXIMACIÓN AL TEMA}

1. La importancia de la jurisprudencia del Tribunal de Justicia de la Unión Europea reside en tres puntos fundamentales, a lo que creo, un primer punto resulta ya de su aplicación directa, aunque sólo en las relaciones verticales y muy dudosamente en las horizontales (esto es, en las relaciones entre particulares).

Un segundo, es su reconocimiento legal expreso, pues puede ser base para interponer el recurso de casación para la unificación de doctrina (artículo 219.2 de la Ley Reguladora de la Jurisdicción Social ${ }^{1}$ ), ya que «[p]odrá alegarse como doctrina de contradicción la establecida en las sentencias dictadas por el Tribunal Constitucional y los órganos jurisdiccionales instituidos en los Tratados y Acuerdos internacionales en materia de derechos humanos y libertades fundamentales ratificados por España, siempre que se cumplan los presupuestos del número anterior referidos a la pretensión de tutela de tales derechos y libertades», lo que incrementa su trascendencia, puesto que la contradicción, con respecto a la doctrina de una Sentencia de las Salas de lo Social de los Tribunales Superiores de Justicia, que se puede alegar para formalizar ese recurso de casación, puede conseguirse directamente, mediante la alegación de una sentencia de este Tribunal, aunque $-\mathrm{y}$, sobre ello, se insistirá con posterioridad- se presentan problemas cuando dicha doctrina ha sobrevenido tras una primera decisión judicial, esto es, cuando la decisión del alto tribunal comunitario es posterior a la del tribunal de instancia español. Un ejemplo muy frecuente en estos últimos meses, han sido las alegaciones realizadas respecto a las tres Sentencias del Tribunal de Justicia de la Unión Europea sobre los ceses procedentes, por cobertura de la plaza, del personal interino de las Administraciones Públicas, en las que el Tribunal Supremo ha mantenido la procedencia, sin indemnización alguna ${ }^{2}$ de aquéllos, y que el alto tribunal europeo ha considerado que es contrario al derecho comunitario la diferencia entre estos trabajadores temporales y otros indefinidos, lo que se ha interpretado en el sentido de indemnizar con, al menos, veinte días de salario por año trabajado como si de un despido objetivo se tratase; decisión que se ha extendido entre todos los Tribunales

\footnotetext{
${ }^{1}$ Ley $36 / 2011$, de 10 de octubre.

${ }^{2}$ Sin perjuicio de determinadas líneas jurisprudenciales contradictorias, que se produjeron durante la génesis de la actual doctrina vigente.
} 
laborales españoles ${ }^{3} y$, después, el propio Tribunal Supremo, aunque por distintas razones, ha terminado acogiendo dicha postura ${ }^{4}$.

Y el tercero, es que esas sentencias también pueden considerarse «jurisprudencia» a los efectos del artículo 193.c) LJS, esto es, de uno de los motivos para la interposición del recurso de suplicación, pues «[e]l recurso de suplicación tendrá por objeto: [...] c) Examinar las infracciones de normas sustantivas o de la jurisprudencia». Entendida, a los fines de este artículo, como la emanada de las Sentencias reiteradas del Tribunal Supremo, según el concepto que a esta fuente complementaria del ordenamiento jurídico atribuye el artículo 1.6 del Código Civil $^{5}$ y que ahora habría que matizar, incluyendo - de la misma forma que se hace para el nomofiláctico- la posibilidad de una cita de sentencias de, entre otros, el Tribunal de Justicia de la Unión Europea, lo que es un elemento muy importante en un recurso determinante en el ámbito social, donde se han presentado en el año 2015, 399.592 asuntos ante los Tribunales españoles, y de los que 49.315 son recursos de suplicación frente a los 4.741 recursos de casación ${ }^{6}$.

2. La relación de jurisprudencia del Tribunal de la Unión Europea es ingente, pero de las numerosas Sentencias me he permitido realizar una selección de una serie resoluciones (en diferentes materias), empleando el evidente criterio de la novedad o cambio de doctrina, esto es, de aquéllas, que pudiendo trascender a situaciones creadas en España, se produce un cambio hacia posturas diversas de las que se habían consolidado por el Tribunal Supremo, siquiera sea necesario plantear -algunas son muy recientes e incluso se ha planteado una revisión a corto plazo de alguna de ellas ${ }^{7}$-. En particular, voy a detenerme en un somero análisis de las siguientes: (a) el cese de trabajadores temporales (indefinidos no fijos de la Administración) y su derecho a ser

\footnotetext{
${ }^{3}$ Para todas, la Sentencia del Tribunal Superior de Justicia de Galicia de 30 de enero de 2017 -Recurso núm. 4245/2016-.

${ }^{4}$ Véase la Sentencia del Tribunal Supremo de 28 de marzo de 2017 -Recurso de Casación para la unificación de doctrina núm. 1664/2015-.

5 Así, entre otras, las Sentencias del Tribunal Supremo de fechas 28 de mayo de 1999 -Recurso de Casación ordinaria núm. 1140/1998-; 30 de abril de 2001 -Recurso de Casación ordinaria núm. 3215/2000-; 11 de octubre de 2001 -Recurso de Casación para la unificación de doctrina núm. 344/2001-; y 27 de diciembre de 2001 -Recurso de Casación ordinaria núm. 1156/2001-. Todo lo cual se entiende sin perjuicio de la sólida corriente científica que mantiene un criterio opuesto en cuanto al concepto de jurisprudencia [cfr. MARTÍNEZ GIRÓN, J., ARUFE VARELA, A. y CARRIL VÁZQUEZ, X. M., Derecho del Trabajo, $2^{\mathrm{a}}$ edición, Netbiblo (A Coruña, 2006), págs. 24 y ss.; y DE CASTRO MEJUTO, L. $\mathrm{F}$, «La prestación de maternidad por adopción en supuestos de previa convivencia», en Anuario de la Facultad de Derecho de la Universidad de A Coruña. Revista Jurídica Interdisciplinar Internacional, Volumen XV (2011), págs. 727.

${ }^{6}$ Son datos extraídos de Panorámica de la Justicia, del Consejo General del Poder Judicial. Acceso libre: http://www.poderjudicial.es/cgpj/es/Temas/Estadistica-Judicial/Estudios-e-Informes/Panoramica-de-laJusticia.

${ }^{7}$ En este aspecto, resulta significativo que, tras la polémica creada por las Sentencias sobre los interinos, se produjesen unas manifestaciones del presidente del Alto Tribunal europeo en las que el Sr. Lenaerts, reconocía que en la sentencia sobre las indemnizaciones por despido a los interinos -la conocida como caso De Diego Porras,- "no hubo entendimiento sobre el problema entre el juzgado que realizó la consulta y los miembros de la Corte de Justicia Europea, y no comprendieron completamente el problema" y añadió que "Soy consciente de esta situación. Esta historia no ha terminado. Hemos enviado este caso a una Sala de tres jueces pensando que el problema estaba claramente expuesto en la cuestión prejudicial y que la respuesta era la correcta, pero ocurre a veces, que no se entiende correctamente el contexto completo en que se desenvuelve el asunto de referencia. Los jueces debemos ser siempre muy modestos y reconocer estas situaciones". Fuente http://www.eleconomista.es/legislacion/noticias/8163313/02/17/LaJusticia-europea-reconoce-que-ha-patinado-en-su-fallo-sobre-la-indemnizacion-por-despido-de-losinterinos.html [consultado el 17/02/17].
} 
resarcidos como el personal indefinido; (b) la posible discriminación que entraña el despido de trabajadores durante su incapacidad temporal, sobre todo, cuando ésta va a ser larga; (c) la valoración de los límites máximos de edad fijados en el acceso a las Fuerzas y Cuerpos de Seguridad del Estado; (d) el cálculo de los umbrales de los despidos colectivos, bajo la perspectiva del cómputo por centro de trabajo o por empresa total; (e) ciertos pronunciamientos relativos a la maternidad y al ejercicio de los derechos de conciliación personal, familiar y personal; (f) el uso del velo islámico en el lugar de trabajo y las posibilidades de un veto empresarial a su empleo en empresas de atención al público; y (g) el acceso al trabajo -solicitud de ingreso en una empresasólo para solicitar una indemnización por discriminación, una vez que no se ha superado el tamiz del proceso de selección.

Naturalmente, la selección efectuada es exclusivamente eso, una mera elección de la ingente cantidad de resolución que se dictan por el Tribunal de Justicia y que responden a un criterio meramente personal, orientado al área de Derecho del Trabajo.

\section{CASOS RECIENTES DEL TRIBUNAL DE JUSTICIA DE LA UNIÓN EUROPEA SOBRE DETERMINADOS TEMAS CON DIRECTA INCIDENCIA EN ESPAÑA:}

\section{El cese de trabajadores temporales de la Administración Pública}

3. El pasado 14 de septiembre de 2016 el Tribunal de Justicia de la Unión Europea dictó tres sentencias (en los Asuntos C-596/14, 184/15 y C-197/15 -acumulados- y C-16/15), en los que vino -aparentemente- a alterar el sistema de ceses de los interinos y temporales de la Administración Pública. El supuesto de hecho que da lugar a la primera de las Sentencias, que es la conocida como caso De Diego Porras, es bastante sencillo: la Sra. De Diego Porras llevaba trabajando como interina para el Ministerio de Defensa una serie de años (nueve, para ser exactos) y en sustitución de otra trabajadora que se encontraba «en situación de dispensa de obligaciones laborales vinculada a su condición sindical»-liberada sindical-; en un momento determinado, se produce la reincorporación de la trabajadora sustituida, a causa de las medidas legales de restricción del gasto público adoptadas allá por el año 2012; lo que provocó el cese de la Sra. De Diego, sin que se le reconocieses ninguna indemnización. La citada trabajadora presentó demanda por despido, que fue desestimada por el Juzgado de lo Social competente y, recurrida en suplicación, la Sala de lo Social el Tribunal Superior de Justicia de Madrid, al conocer del recurso, se plantea una cuestión prejudicial, partiendo de que el cese de la actora fue legalmente correcto. La lectura del Auto del Tribunal Superior de Justicia de Madrid de 9 de diciembre de 2014 -Recurso contenciosoadministrativo núm. 246/2014-, la cuestión planteada se refiere a la exclusión de la indemnización y se relaciona con lo dispuesto en el artículo 49.1.c) del Estatuto de los Trabajadores $^{8}$, que no fija ninguna indemnización, a diferencia de otros contratos

\footnotetext{
${ }^{8}$ «1. El contrato de trabajo se extinguirá: [...] c) Por expiración del tiempo convenido o realización de la obra o servicio objeto del contrato. A la finalización del contrato, excepto en los casos del contrato de interinidad y de los contratos formativos, el trabajador tendrá derecho a recibir una indemnización de cuantía equivalente a la parte proporcional de la cantidad que resultaría de abonar doce días de salario por
} 
temporales en los que se establece una de doce días de salario por año trabajado, para la extinción por vencimiento del término de los contratos de interinidad.

La argumentación empleada se basa en que la Directiva 1999/70, del Consejo, de 28 de junio de 1999, relativa al Acuerdo marco de la CES, la UNICE y el CEEP sobre el trabajo de duración determinada, no permite tratar a los trabajadores temporales «de una manera menos favorable que a los trabajadores fijos comparables por el mero hecho de tener un contrato de duración determinada»-Cláusula 4 del Acuerdo Marco que la desarrolla-; por lo que para establecer un régimen jurídico distinto a fijos y temporales (en este caso, dos escalas de indemnización al término del contrato) debe haber las que denomina «razones objetivas»-que es el primero de los dos conceptos claves en la fundamentación de la Sentencia-. El Tribunal de Justicia de la Unión Europea fija que, para que puedan alegarse esas «razones objetivas», la desigualdad de trato que es analiza debe estar «justificada por la existencia de elementos precisos y concretos», excluyéndose -además- que la mera «la naturaleza temporal de la relación laboral» pueda constituir per se una razón objetiva justificativa. En definitiva, es preciso que haya algo más, un plus, al margen del simple dato del carácter interino -temporal- del contrato, para permitir que se ofrezca un trato diferente a temporales e indefinidos, al menos, en el aspecto indemnizatorio, en lo que tiene que ver con la indemnización por despido. Y el segundo de los elementos clave es la denominada «situación comparable», que se define en el apartado 40 de manera muy general, porque se indica que: «[p]ara apreciar si las personas de que se trata ejercen un trabajo idéntico o similar, en el sentido del Acuerdo marco, debe comprobarse si, en virtud de las cláusulas 3, apartado 2, y 4, apartado 1, de éste, habida cuenta de un conjunto de factores, como la naturaleza del trabajo, los requisitos de formación y las condiciones laborales, puede considerarse que estas personas se encuentran en una situación comparable (sentencias de 18 de octubre de 2012, Valenza y otros, C-302/11 a C-305/11, EU:C:2012:646, apartado 42 y jurisprudencia citada, y de 13 de marzo de 2014, Nierodzik, C-38/13, EU:C:2014:152, apartado 31)».

En consecuencia, si concurriese alguna de las dos circunstancias anteriores (o bien la situación no fuese comparable o bien existen razones objetivas), sí sería posible -desde el punto de vista del derecho europeo- la diferenciación de condiciones entre trabajadores temporales e indefinidos. El problema -naturalmente, y ya se adivina- es que ello parecía abocar a una judicialización de las discusiones sobre los dos conceptos citados, de tal forma que tendría que analizarse caso por caso, empresa por empresa, para saber si el trabajo que desempeñan fijos y temporales son «comparables»; algo que -pese a todo- no se ha producido 9 .

4. La cuestión más interesante es si esa doctrina puede aplicarse directamente en los recursos que están en trámite, esto es, si en asuntos que se han resuelto ya -conforme a la doctrina tradicional española y expresada en el citado artículo 49.1.c) del Estatuto de

cada año de servicio, o la establecida, en su caso, en la normativa específica que sea de aplicación» [art. 49.1.c) ET].

${ }^{9}$ Cfr. LÓPEZ BALAGUER, M., «La aplicación de la doctrina «De Diego Porras» al contrato para obra o servicio determinado en el ámbito privado. STSJ País Vasco, de 18 de octubre de 2016 (AS 2016, 1446)», en Revista Española de Derecho del Trabajo, núm. 195, 2017, consultado a través de la base de datos Westlaw (BIB 2017/489). 
los Trabajadores-, se puede alegar en el recurso que se interponga la Sentencia del Tribunal de Justicia de la Unión Europea de 14 de septiembre de 2016 o no. El Tribunal Supremo todavía no se ha pronunciado sobre este tema, de hecho, ha dejado la puerta abierta a la posibilidad de que pueda ser empleado en otros pronunciamientos, dado que la Sentencia del Tribunal Supremo de 7 de noviembre 2016 -Recurso de Casación para la unificación de doctrina núm. 755/2015-, indica que por motivos cronológico no puede hacerlo, pero sin descartar su futuro empleo argumentativo; así: «No es este el momento de pronunciarnos sobre los efectos que sobre esta materia haya de producir la reciente STJUE de 14 de septiembre de 2016 (Asunto De Diego Porras, C- 596/14 ), ya que quien recurre es la parte demandada y, por consiguiente, no se suscita aquí la cuestión del importe de la indemnización. Sin embargo, sí hemos de estar a los criterios que hemos venido estableciendo en relación con las consecuencias del cese de los trabajadores indefinidos no fijos del sector público»; aunque ya posteriormente acoge dichas consecuencias -el incremento de la indemnización a los indefinidos no fijos-, siquiera en base a otros razonamientos ${ }^{10}$, y así: «Primera. Porque la figura del indefinido no fijo, aunque es una creación jurisprudencial, ya es recogida en la Ley, el Estatuto Básico del Empleado Público (EBEP), aprobado por RDL 5/2015, de 30 de octubre, cuyos artículos 8 y 11-1 nos muestran que la norma diferencia al personal laboral en función de la duración de su contrato en fijo, por tiempo indefinido o temporal, pues en otro caso no habría empleado el vocablo indefinido y sólo habría distinguido entre fijos y temporales, lo que conlleva que el personal indefinido no sea equiparable al temporal. Segunda. Porque el origen de la figura del personal indefinido, no fijo, se encuentra en un uso abusivo de la contratación temporal por parte de algún órgano administrativo. Cuando ese uso abusivo de la contratación temporal se lleva a cabo por empresas privadas el contrato se convierte en fijo, (art. 15, números 3 y 5, del ET), pero cuando lo hace la Administración, como el acceso a la función pública y a un empleo público en general debe hacerse con escrupuloso respeto de los principios de igualdad, mérito y capacidad (artículos 103 de la Constitución y 9-2, 11-2, 55, 70 y demás concordantes del Estatuto Básico del Empleado Público), no puede imponerse esa novación sancionadora de la relación jurídica, por cuanto se facilitaría, igualmente, un acceso fraudulento a un empleo público, al eludirse la aplicación de las normas que velan por el acceso a esos puestos funcionariales y laborales, mediante concursos públicos en los que se respeten los principios de igualdad, mérito y capacidad. Tercera. Porque, cual se deriva de lo señalado, la figura jurídica del contrato indefinido-no fijo es diferente del contratado temporal y del fijo, lo que plantea el problema de cuál debe ser la indemnización que le corresponda por la rescisión de su contrato por la cobertura reglamentaria de la plaza ocupada, por cuanto, al no tratarse de un contrato temporal, parece insuficiente la que hasta ahora le hemos venido reconociendo con base en el art. 49-1-c) del ET, pues, dadas las causas que han motivado la creación de esta institución, parece necesario reforzar la cuantía de la indemnización y reconocer una superior a la establecida para la terminación de los contratos temporales, pues el vacío normativo al respecto no justifica, sin más, la equiparación del trabajador indefinido-no fijo a temporal como hemos venido haciendo. Cuarta. Tal como hemos señalado, la ausencia de un régimen jurídico propio del contrato indefinido no fijo, que el EBEP se ha limitado a reconocer sin establecer la pertinente regulación de sus elementos esenciales -en este caso, el régimen extintivo- obliga a la Sala a resolver el debate planteado en torno a la indemnización derivada de la extinción de tal contrato, cuando la misma se produce por la cobertura reglamentaria de la plaza. En este sentido, acudiendo a

\footnotetext{
${ }^{10}$ Véase la Sentencia del Tribunal Supremo de 28 de marzo de 2017 -Recurso de Casación para la unificación de doctrina núm. 1664/2015-.
} 
supuestos comparables, es acogible la indemnización de veinte días por año de servicio, con límite de doce mensualidades, que establece el artículo 53.1-b) del ET en relación a los apartados c) y e) del artículo 52 del mismo texto legal para los supuestos de extinciones contractuales por causas objetivas. La equiparación no se hace porque la situación sea encajable exactamente en alguno de los supuestos de extinción contractual que el referido artículo 52 ET contempla, por cuanto que ese encaje sería complejo, sino porque en definitiva la extinción aquí contemplada podría ser asimilable a las que el legislador considera como circunstancias objetivas que permiten la extinción indemnizada del contrato».

Los Tribunales Superiores de Justicia sí han planteado la aplicación directa de la doctrina, porque todavía - a la fecha de redacción de este artículo- no han llegado pleitos así planteados en Instancia, sino asuntos donde al hilo del recurso de suplicacuón se plantea la indemnización o se cita la S Tribunal de Justicia de la Unión Europea por la vía del artículo 233 de la Ley Reguladora de la Jurisdicción Social, que es la que permite la incorporación de documentos. $\mathrm{Y}$ ante este planteamiento, con alguna excepción, la postura ha sido favorable al empleo de la nueva doctrina europea; alguna excepción, de la que es un claro exponente la Sentencia del Tribunal Superior de Justicia de Cataluña de 30 de diciembre de 2016, dictada en el Recurso núm. 3593/2016 y, de ahí su valor, en Sala General, que es cuando se resuelve el recurso por el Tribunal constituido por la totalidad de sus Magistrados. Las razones esgrimidas por ese tribunal para rechazar la aplicación directa de la doctrina europea han sido que, de hacerlo en trámite de recurso, se produciría una incongruencia, ya que no cabe estimar de oficio la novedosa indemnización, pues ninguna de las partes planteó esta cuestión en Instancia y el trabajador tampoco solicitó otro tipo de indemnización alternativa para el caso de que la finalización de su contrato fuese declarada ajustada a Derecho. En definitiva, se concluye que no se puede condenar al pago de una indemnización no pedida en la Instancia y que no tiene vínculo directo o indirecto con la pretensión de despido; aunque se deja una puerta abierta, puesto que, apunta, no obstante, a que el empleado cesado pueda instar nuevo proceso, pero ya no de despido, sino uno ordinario, de reclamación de cantidad, para solicitar aquello a lo que pudiese tener derecho de haberse aplicado la doctrina del asunto De Diego Porras o, incluso - es otra alternativa- plantear una reclamación de daños y perjuicios provocados por la incorrecta transposición de la Directiva 1999/70, del Consejo, de 28 de junio de 1999, relativa al Acuerdo marco de la CES, la UNICE y el CEEP sobre el trabajo de duración determinada, por parte del Estado español.

5. Cuestión interesante en este punto es también si dicha doctrina se aplica sólo a las relaciones entre empleado y empresa pública o si el efecto se extiende a las relaciones entre particulares; aspecto en el que difieren las doctrinas de los Tribunales Superiores de Justicia de Andalucía (Sentencias todas de 16 de noviembre de $2016^{11}$ ) y del País Vasco (dos de 18 de octubre de $2016^{12}$ ). En el sector privado, esto es, la aplicación respecto de empresas privadas, mientras el Tribunal Superior de Justicia del País Vasco reconoce la indemnización de veinte días de salario por año de servicio en supuestos de válidas extinciones de contratos temporales, el Tribunal Superior de Justicia de

\footnotetext{
${ }^{11}$ Sentencias del Tribunal Superior de Justicia de Andalucía/Málaga de 16 de noviembre de 2016 Recurso núm. 1411/2016-, 16 de noviembre de 2016 -Recurso núm. 1515/2016-, 16 de noviembre de 2016 -Recurso núm. 1532/2016- y 16 de noviembre de 2016 a -Recurso núm. 1539/2016-

12 Sentencias del Tribunal Superior de Justicia del País Vasco de 18 de octubre de 2016 -Recurso núm. 1872/2016- 18 de octubre de 2016 -Recurso núm. 1690/2016-
} 
Andalucía/Málaga mantiene que, siquiera corresponderían esos veinte días de indemnización, las Directivas no tienen un efecto horizontal -al que se hacía referencia en el $\S 1-$, salvo en lo que se refieren a las políticas antidiscriminación ${ }^{13}$, ello implica que sólo se pueden reconocer doce días de salario por año trabajado, de tal forma que el trabajador, de querer reclamar los otros ocho días, sería preciso que acudiese a un proceso por responsabilidad patrimonial del Estado (por transposición defectuosa de la normativa comunitaria), que debería seguirse ante la jurisdicción contencioso administrativa y no ante la social -de acuerdo con el artículo 2.e) de la Ley 29/1998, de Jurisdicción Contencioso-Administrativa-. Sin embargo, en el caso de que el trabajador haya prestado servicios para un empleador considerado administración pública, las doctrinas sin embargo son coincidentes, de tal forma que se reconoce en los supuestos contemplados la indemnización de veinte días correspondientes a un despido objetivo procedente, sin que se considere que la alegación de la doctrina comunitaria en vía de recurso altere la congruencia de la decisión. Otros ejemplos, que podrían citarse son las Sentencias del Tribunal Superior de Justicia de Asturias de 8 de noviembre de 2016 Recurso núm. 2142/2016-, referida a un indefinido no fijo cuyo cese se produce por la cobertura de la plaza, y de Madrid de 5 de octubre de 2016 -Recurso núm. 246/2014-, concerniente a un interino por sustitución cuyo titular reingresa.

En lo que respecta a Galicia, se podrían citar dos ejemplos, la Sentencia del Tribunal Superior de Justicia de Galicia de 30 de enero de 2017 -Recurso núm. 4245/2016- y la de 17 de febrero de 2017 -Recurso núm. 4819/16, relativos, respectivamente, a un supuesto -bastante frecuente- de asignación de un personal indefinido a un puesto de trabajo de funcionario, de tal forma que dicha plaza, que ya estaba ofertada, se ocupará temporalmente; lo que se ha considerado por la jurisprudencia como bien ejecutado, dado que la Administración tiene una capacidad de autoorganización que no se puede ver restringida en cuanto a las necesidades de cobertura de plazas. Sin embargo, después, se incorpora el funcionario a su plaza - la ocupada por el indefinido- y se le cesa; tesitura ante la que el alto tribunal gallego entiende válido el cese, pero indemnizable con veinte días de salario, como si de un despido objetivo se tratase. Y, la segunda sentencia citada, se refería a un supuesto de ocupación de plaza de interino, que es cubierta por otro empleado con derecho de reserva de puesto de trabajo, al que se adscribe temporalmente a la plaza ocupada interinamente, porque la suya estaba ocupada; nuevamente, el cese es considerado válido, pero indemnizable con la indemnización del despido objetivo.

En estas Sentencias se planteó la posible incongruencia respecto del planteamiento en la Instancia, pero se descartó bajo el argumento de que quien pide lo más, pide lo menos; $\mathrm{y}$ ello, es aplicable sin duda en el campo laboral ${ }^{14}$. Es decir, quien reivindica una indemnización de cuarenta y cinco o treinta y tres días por año de servicio, según los casos, igualmente está solicitando una suma inferior por ese mismo concepto en la práctica (veinte días días). De ahí la jurisprudencia que considera adecuado asignar

\footnotetext{
${ }^{13}$ Cfr. CANTO GARCÍA, M., «El efecto directo horizontal en las directivas y el Tratado de Maastricht», en Boletín de Información. Ministerio de Justicia e Interior, núm. 1730-31, 1995, pág. 196 y ss.; y MILLÁN MORO, L., «La eficacia directa de las directivas: evolución reciente», en Revista de Instituciones Europeas, volumen 18, núm. 3, 1991, págs. 845 y ss. Podrían citarse las Sentencias del Tribunal de Justicia de la Unión Europea en los casos Mangold y Danks Industri, citadas por la Sentencia del Tribunal Supremo de 8 de junio de 2016 -Recuso de casación ordinaria núm. 207/2015-.

${ }^{14}$ Para todas, Sentencia del Tribunal Supremo de 31 de octubre de 2003 -Recurso de Casación para la unificación de doctrina núm. 17/2002
} 
ocho días al trabajador demandante por un despido que se declara inexistente ${ }^{15}$; y, desde luego, en ninguna de ellas se dudó de la aplicación de la Directiva, puesto que el Auto del Tribunal de Justicia de la Unión Europea de 11 diciembre 2014 (Asunto León Medialdea v. Ayuntamiento de Huétor Vega, C-86/149), que da respuesta a una cuestión prejudicial española, deja patente que los denominados trabajadores indefinidos no fijos se hallan incluidos en el marco de la Directiva 1999/70/CE del Consejo, de 28 de junio de 1999, relativa al Acuerdo marco de la CES, la UNICE y el CEEP sobre el trabajo de duración determinada.

6. De lo expresado se puede extraer una conclusión: el poco conocimiento que existe en Europa de nuestro derecho, lo que se aúna a una rácana explicación por parte del Gobierno español para justificar la diferencia de trato entre trabajadores temporales y trabajadores indefinidos, habida cuenta que se limitó a residenciarlos en su duración y en la expectativa de estabilidad. Y, por extensión, la poca importancia que el Tribunal de Justicia le ha dado a las tres cuestiones prejudiciales planteadas por España (consideradas por algunos, la famosa trilogía sísmica), que se justifica en que las tres sentencias son del mismo día, cuentan con el mismo ponente, han sido instruidas únicamente por tres jueces (en lugar de cinco o quince) y no existen conclusiones del abogado general ${ }^{16}$. Ahora bien, ante el revuelo producido se ha expresado por el Presidente del tribunal europeo, el Sr. Lenaerts, la posibilidad de que se reconsidere la postura inicial, ante la falta de entendimiento de la figura de los contratados temporales de las Administraciones Públicas en España ${ }^{17}$, aunque -todo hay que decirlo- es la opinión del que ocupa dicha presidencia, pero no la del órgano judicial y todo habrá que ver si dicha postura se reconsidera o se hacen pronunciamientos extensivos a otras instituciones (por ejemplo, a los contratos de relevo ${ }^{18}$ ).

En realidad, lo que esconde todo esto es un desproporcionado, enorme, abuso de la figura de los temporales en nuestro país, que no se emplean para la función para la que han sido pensados: cubrir una necesidad no permanente, sino para hacerlo con otras estructurales, pese al avance que ha supuesto tanto la redacción del artículo 15.5 del Estatuto de los Trabajadores como la interpretación que se ha hecho del artículo 70 del Estatuto Básico del Empleado Público (Real Decreto Legislativo 5/2015, de 30 de octubre, por el que se aprueba el texto refundido de la Ley del Estatuto Básico del Empleado Público ${ }^{19}$ ), que han supuesto la conversión judicial en indefinidos de los

\footnotetext{
${ }^{15}$ Véanse las Sentencias del Tribunal Supremo de 14 de octubre de 2013 -Recurso de Casación para la unificación de doctrina núm. 68/2013-; 24 de junio de 2014 -Recurso de Casación para la unificación de doctrina núm. 217/2013-; y 6 de octubre de 2015 -Recurso de Casación para la unificación de doctrina núm. 2592/2014-.

${ }^{16}$ Cfr. PANEA HERNANDO, D. J., «Nuevas sentencias a raíz del asunto "De Diego Porras”», en Centro de Estudios Financieros, accesible en http://www.laboral-social.com/nuevas-sentencias-asunto-diegoporras.html.

${ }_{17}^{17}$ Se adelantaban sus manifestaciones en un periódico digital.

${ }^{18}$ Sobre la que se ha planteado una cuestión prejudicial por el Tribunal Superior de Justicia de Galicia, Auto de 5 de abril de 2017-Recurso núm. 4812/2016-.

19 «Las necesidades de recursos humanos, con asignación presupuestaria, que deban proveerse mediante la incorporación de personal de nuevo ingreso serán objeto de la Oferta de empleo público, o a través de otro instrumento similar de gestión de la provisión de las necesidades de personal, lo que comportará la obligación de convocar los correspondientes procesos selectivos para las plazas comprometidas y hasta un diez por cien adicional, fijando el plazo máximo para la convocatoria de los mismos. En todo caso, la ejecución de la oferta de empleo público o instrumento similar deberá desarrollarse dentro del plazo improrrogable de tres años» (art. 70 EBEP).
} 
temporales que lleven más de tres años en la plaza ${ }^{20}$. Como reflejo de ello, se podría recordar - un poco lejana ya- la Sentencia del Tribunal de Justicia de la Unión Europea 13 de marzo de 2014 (Caso Márquez Somohano c. Universidad Pompeu Fabra), donde se habían producido sucesivas prórrogas de contratos de profesores asociados, que sólo se consideran válidas si responden a "necesidades provisionales, y que no se haya utilizado para cubrir necesidades permanentes y duraderas en materia de contratación de personal docente", porque, de haberse hecho, el contrato sería indefinido y temporal.

7. Y en cuanto a las consecuencias derivadas, que algunos han cifrado en el establecimiento en el futuro de un contrato único, podrían recordarse las acertadas reflexiones expresadas por DESDENTADO BONETE ${ }^{21}:$ :La repercusión económica de la sentencia no es desdeñable: tiene una incidencia sensible con un incremento del $40 \%$ en el multiplicador de la fórmula de la indemnización. Pero no afecta a los demás componentes de ésta (salario y antigüedad), que suelen ser bajos en los contratos temporales, lo que amortiguará los efectos en el incremento de los costes. Se ha dicho que la sentencia podría suponer la instauración del contrato único por vía judicial. No creo que sea así, porque faltan los elementos esenciales del contrato único en su segunda versión: las indemnizaciones crecientes con salida y ritmo de progresión más moderado y la reducción del "gap" entre procedencia e improcedencia para rebajar los efectos de la causalidad». Por otra parte, «Se hace necesario pues, una reforma de la legislación nacional que aborde los siguientes aspectos. Primero. Eliminación de los supuestos en los que se permite la utilización de contratos de duración determinada para atender a necesidades de personal permanentes, en sectores tales como la sanidad o la educación. Segundo. Se precisa una regulación de las consecuencias que debe conllevar la utilización sucesiva de contratos de duración determinada en sectores específicos, como pueden ser las Administraciones Públicas [...] Tercero. Debe hacerse extensible a todos los trabajadores temporales que presten servicios en régimen de Derecho administrativo para las Administraciones Públicas, la doctrina del Tribunal Supremo sobre la conversión en indefinidos de los trabajadores temporales cuyas relaciones laborales se encuentren en fraude de ley (indefinidos no fijos)» ${ }^{22}$.

\section{El despido durante la incapacidad temporal}

8. La postura tradicional en la jurisprudencia española ha sido negar la existencia de discriminación en los supuestos de despido de un trabajador en situación de incapacidad temporal, en atención a su disminución de su productividad, derivada de su reducción funcional inherente a su incapacidad temporal, porque el despido se ha considerado improcedente por regla general. Sólo «cuando el factor enfermedad sea tomado en

\footnotetext{
${ }^{20}$ Para todas, véase la Sentencia del Tribunal Superior de Justicia de Galicia de 23 de junio de 2016 Recurso núm. 324/2016-.

21 Véase DESDENTADO BONETE, A., «¿Un miércoles de ceniza para la contratación temporal española? Reflexión breve sobre la sentencia del Tribunal de Justicia de la Unión Europea en el caso de Diego Porras», en Revista de Información Laboral, núm. 10, 2016, consultado a través de la base de datos Westlaw (BIB 2016180436).

${ }^{22}$ Véase RODRÍGUEZ CRESPO, M. J., «Límites al uso abusivo de la contratación temporal por parte de las Administraciones Públicas. Un análisis a la luz de los recientes pronunciamientos del TJUE: asuntos María Elena López contra el Servicio Madrileño de Salud y Martínez Andrés (C-16/15) y Otro contra el Servicio Vasco de Salud (C-184/15)», en Revista de Información Laboral, núm. 4, 2017, consultado a través de la base de datos Westlaw (BIB 2017/11073).
} 
consideración como un elemento de segregación basado en la mera existencia de la enfermedad en sí misma considerada o en la estigmatización como persona enferma de quien la padece, al margen de cualquier consideración que permita poner en relación dicha circunstancia con la aptitud del trabajador para desarrollar el contenido de la prestación laboral objeto del contrato», podrá «constituir un factor de discriminación análogo a los expresamente contemplados en el art. $14 \mathrm{CE}$, encuadrable en la cláusula genérica de las otras circunstancias o condiciones personales o sociales contemplada en el mismo» ${ }^{23}$. De hecho, las afirmaciones mantenidas van en el sentido de sostener que la enfermedad no constituye factor de discriminación, aunque lo sea de trato ilegal; por ello, cuando se produce el despido de un enfermo, el despido ha de calificarse como improcedente y no como nulo ${ }^{24} ;$ y así, «[...] la calificación de despido improcedente es la que resulta aplicable [...], cuando no se está en ninguno de los supuestos del artículo 108.2 de la Ley de Procedimiento Laboral [...] En la afirmación contraria [...] se confunden dos principios constitucionales -el principio de igualdad de trato y la tutela antidiscriminatoria- que tienen un distinto alcance [se citan las SSTS 17/10/90 Ar. 7929; 23/09/93 Ar. 7032; y 17/05/00 Ar. 5513) [...] [y] la referencia del inciso final del artículo 14 de la Constitución no puede interpretarse en el sentido de que comprenda cualquier tipo de condición o de circunstancia, pues en ese caso la prohibición de discriminación se confundiría con el principio de igualdad de trato afirmado de forma absoluta. Lo que caracteriza la prohibición de discriminación [...], es [...] que en ella se utiliza un factor de diferenciación que merece especial rechazo por el ordenamiento [...], porque para establecer la diferencia de trato se toman en consideración condiciones que históricamente han estado ligadas a formas de opresión o de segregación de determinados grupos de personas o que se excluyen como elementos de diferenciación para asegurar la plena eficacia de los valores constitucionales en que se funda la convivencia en una sociedad democrática y pluralista. La enfermedad, [...] desde una perspectiva estrictamente funcional de incapacidad para el trabajo, [...], no es un factor discriminatorio en el sentido estricto [...], aunque pudiera serlo en otras circunstancias en las que resulte apreciable el elemento de segregación. [...]. Tampoco resulta aquí aplicable la garantía del artículo 4.2.c). $2^{\circ}$ del Estatuto de los Trabajadores, porque ni consta que el actor haya sido declarado minusválido, ni el despido se ha producido en atención a una minusvalía sin repercusión en la aptitud para el trabajo, sino en atención a los períodos de baja en el trabajo y la consiguiente pérdida para la empresa de interés productivo en el trabajador» 25 .

Esta línea doctrinal se ha mantenido incólume, pese al tiempo transcurrido, y muestra de ello, puede citarse la Sentencia del Tribunal Supremo de 3 de mayo de 2016 -Recurso de Casación para la unificación de doctrina núm. 3348/2014-, donde se analizaba el despido de una trabajadora que sufría un accidente de trabajo que le provoca un latigazo cervical, inicia un proceso de incapacidad temporal y la despiden diez días más tarde; y se rechaza su consideración como nulo, reiterando que, a los efectos de la calificación del despido, la enfermedad no constituye factor de discriminación, aunque lo sea de trato ilegal, por lo que la decisión extintiva por dicha causa no integra la nulidad. El

\footnotetext{
${ }^{23}$ Son palabras de la Sentencia del Tribunal Constitucional 62/2008, en su fundamento jurídico 6.

${ }^{24}$ Reiterando precedentes las Sentencias del Tribunal Supremo de noviembre de 1993 -Repertorio de Jurisprudencia Aranzadi núm. 8346-; 19 de enero de 1994 -Repertorio de Jurisprudencia Aranzadi núm. 352-; 23 de mayo de 1996 -Repertorio de Jurisprudencia Aranzadi núm. 4612-; 30 de diciembre de 1997 -Repertorio de Jurisprudencia Aranzadi núm. 1998/447-.

25 Son palabras de las Sentencias del Tribunal Supremo de 29 de enero de 2001 -Repertorio de Jurisprudencia Aranzadi núm. 2069-; 23 de septiembre de 2002 -Repertorio de Jurisprudencia Aranzadi núm. 449-; y 12 de julio de 2004 -Repertorio de Jurisprudencia Aranzadi núm. 7075-.
} 
motivo -en suma- es que «la enfermedad, sin adjetivos o cualificaciones adicionales, es una situación contingente de mera alteración de la salud, que puede y suele afectar por más o menos tiempo a la capacidad de trabajo del afectado. Como es de experiencia común, el colectivo de trabajadores enfermos en un lugar o momento determinados es un grupo de los llamados efímeros o de composición variable en el tiempo. La discapacidad es, en cambio, una situación permanente de minusvalía física, psíquica o sensorial, que altera de manera permanente las condiciones de vida de la persona discapacitada. En concreto, en el ordenamiento español la discapacidad es considerada como un 'estatus' que se reconoce oficialmente mediante una determinada declaración administrativa, la cual tiene validez por tiempo indefinido. Parece claro, a la vista de las indicaciones anteriores, que las razones que justifican la tutela legal antidiscriminatoria de los discapacitados en el ámbito de las relaciones de trabajo no concurren en las personas afectadas por enfermedades o dolencias simples. Estos enfermos necesitan curarse lo mejor y a la mayor brevedad posible. Los discapacitados o aquejados de una minusvalía permanente, que constituyen por ello un grupo o colectivo de personas de composición estable, tienen en cambio, como miembros de tal grupo o colectividad, unos objetivos y unas necesidades particulares de integración laboral y social que no se dan en las restantes dolencias o enfermedades».

9. Sin embargo, esta concepción cambia radicalmente, porque, al considerar el Tribunal de Justicia de la Unión Europea que las situaciones de incapacidad temporal con determinadas características son acreedoras de la calificación de discapacidad, deben entenderse como discriminatorias las extinciones de los contratos de trabajo de trabajadores en dicha situación, habida cuenta que -a nivel de legalidad ordinaria- se reconocen expresamente como discriminatorios los despidos que afectan a empleados por motivo de su discapacidad [artículos 14 de la Constitución Española, 4.2.c) ${ }^{26}$ y 17.1 del Estatuto de los Trabajadores]; siquiera la discrepancia no se produce sobre la mera enfermedad «sin cualificaciones adicionales», porque no la considera ni un factor de discriminación ni la equiparar a discapacidad; sino que dicha discrepancia se produce en el concepto de discapacidad que se ha venido utilizando, porque el Tribunal Supremo acogió un concepto muy restrictivo de discapacidad, que cifra en «una situación de minusvalía permanente», que altera también «de manera permanente las condiciones de vida de la persona». Es - precisamente- la Sentencia del Tribunal de Justicia de la Unión Europea de 1 de diciembre de 2016, Asunto Daouidi, C-395/15, la que viene a incidir sobre la postura tradicional de la jurisprudencia española, ya que explica que, «a raíz de la ratificación por la Unión de la Convención de la ONU (Decisión 2010/48), el Tribunal de Justicia ha estimado que el concepto de discapacidad en el sentido de la Directiva 2000/78 debe entenderse como referido a una limitación, derivada en particular de dolencias físicas, mentales o psíquicas, a largo plazo, que, al interactuar con diversas barreras, puede impedir la participación plena y efectiva de la persona de que se trate en la vida profesional en igualdad de condiciones con los demás trabajadores». El dato decisivo es -en definitiva- el carácter duradero de la limitación, que debe valorarse en el momento en el que se adopta la decisión extintiva, tomando en cuenta su estado de incapacidad; en otras palabras, el hecho de que a nivel de legislación interna su situación sea una incapacidad temporal, no supone un obstáculo para entenderla duradera, en el sentido de la Directiva 2000/78 y, por lo tanto, discriminatoria la decisión. Por lo tanto, el quid de la cuestión radica en la duración

\footnotetext{
${ }^{26}$ «Los trabajadores [...] en la relación de trabajo [...] tampoco podrán ser discriminados por razón de discapacidad, siempre que se hallasen en condiciones de aptitud para desempeñar el trabajo o empleo de que se trate».
} 
temporal de la limitación de dicha capacidad del trabajador, empleando una serie de indicios en el momento del despido, a saber: «que la incapacidad del interesado no presente una perspectiva bien delimitada en cuanto a su finalización a corto plazo o el que dicha incapacidad pueda prolongarse significativamente antes del restablecimiento de dicha persona» ${ }^{27}$, y para «comprobar ese carácter "duradero", el juzgado remitente debe basarse en todos los elementos objetivos de que disponga, en particular, en documentos y certificados relativos al estado de dicha persona, redactados de los conocimientos y datos médicos y científicos actuales». El caso examinado, referido al planteamiento de una cuestión prejudicial por una órgano judicial español ${ }^{28}$, se refería a un trabajador que había sufrido un accidente de trabajo y, por su causa, debió permanecer en situación de incapacidad temporal durante diez meses, inicialmente sólo escayolado y, después, fue sometido a una intervención quirúrgica. La discriminación se produjo -además-, porque el trabajador no fue despedido en un primer momento, sino posteriormente.

Tres conclusiones se puede extraer de la nueva doctrina: primera conclusión, los despidos simultáneos al comienzo de la baja, donde todavía no existe un criterio formado sobre la eventual duración de la situación de incapacidad, no pueden considerarse discriminatorios a estos efectos, al estar ausente uno de los elementos indispensables empleados por la jurisprudencia comunitaria para hablar de discapacidad: su temporalidad incierta más o menos duradera. A efectos prácticos, las incapacidades temporales de duración temporal reducida no quedarían amparadas por la interpretación comunitaria y, sin embargo, las que la tengan prolongada o, cuando menos, incierta, sí, salvo que el despido se adopte en el mismo momento de su concurrencia. Segunda conclusión, la declaración de nulidad comporta la readmisión del trabajador en sus previas condiciones de trabajo (artículo 55.6 del Estatuto de los Trabajadores $^{29}$ ), aunque la empresa estará obligada a realizar las adaptaciones necesarias en el puesto de trabajo y, además, el abono de una indemnización por los eventuales daños morales producidos por el despido. Y tercera conclusión, puesto que el despido será considerado nulo, se produce la llamada inversión de la carga de la prueba, esto es, probado el indicio de que dicho despido responde a una causa espuria como es discriminar a un discapacitado- será el empresario el que venga obligado a probar que la decisión, precisamente, tiene una causa ajena, objetiva y proporcional para ello $^{30}$. En particular, el órgano que planteó la cuestión prejudicial apreció nulidad en el despido del Sr. Daouidi ${ }^{31}$, pero, recurrida en suplicación, la Sentencia del Tribunal Superior de Justicia de Cataluña de 12 de junio de 2017 -Recurso núm. 2310/17- revocó dicha resolución y estimando el recurso planteado por la empleadora rechaza la nulidad y aprecia únicamente la improcedencia, basándose en el escaso tiempo transcurrido

\footnotetext{
${ }^{27}$ Apartado 56.

${ }^{28}$ En concreto, el Juzgado de lo Social núm. Treinta y tres de Barcelona en los Autos 1291/2014.

${ }^{29}$ «El despido nulo tendrá el efecto de la readmisión inmediata del trabajador, con abono de los salarios dejados de percibir» (art. 55.6 ET).

${ }^{30}$ Sobre el tema podrían consultarse, DESDENTADO DAROCA, E., «El despido del enfermo y la STJUE de 1 de diciembre de 2016 dictada en el caso Daouidi. Algunas reflexiones críticas», en Revista de Información Laboral, núm. 3, 2017, consultado a través de la base de datos Westlaw (BIB 2017/1107); y SÁNCHEZ PÉREZ, J., «El despido del trabajador en situación de incapacidad temporal: el derecho al rendimiento empresarial frente al derecho de protección de la salud», en Revista de Información Laboral, núm. 5, 2017, consultado a través de la base de datos Westlaw (BIB 2017/11172).

${ }^{31}$ Cfr. Sentencia del Juzgado de lo Social núm. Treinta y tres de Barcelona de 23 de diciembre de 2016, Autos núm. 1219/2014.
} 
desde el inicio de la incapacidad temporal hasta la fecha del despido y en la doctrina tradicional del Tribunal Supremo.

\section{La discriminación por razón de edad en el acceso a determinadas profesiones}

10. Un nuevo pronunciamiento del alto tribunal europeo, su Sentencia de 15 de noviembre de 2016, asunto Salaberría Sorondo, C-258/15, ha vuelto a analizar el difícil tema de la discriminación por razón de edad en el acceso a los empleos; afirmando -en suma- que esa prohibición de trabajar por haber cumplido determinados años solo es posible si existe una justificación objetiva y razonable; circunstancia -además- que debe acreditarse. El supuesto se refería a la selección de agentes de la Ertzaintza, que estaba limitada a aquéllos candidatos que no hubiesen cumplido los treinta y cinco años, y el Tribunal sostiene que «puede considerarse que una norma como la controvertida en el litigio principal, que establece que los candidatos a agentes de la Ertzaintza no deben haber cumplido 35 años, por un lado, es adecuada al objetivo consistente en mantener el carácter operativo y el buen funcionamiento del servicio de policía de que se trata y, por otro, no va más allá de lo necesario para alcanzar este objetivo» ${ }^{32}$, lo que se hace en base a que «el objetivo consistente en mantener el carácter operativo y el buen funcionamiento del servicio de la Ertzaintza exige que, para restablecer una pirámide de edades satisfactoria, la posesión de las capacidades físicas específicas no deba entenderse de manera estática, únicamente durante las pruebas del proceso selectivo, sino de manera dinámica, teniendo en cuenta los años de servicio que prestará el agente después de ser seleccionado» ${ }^{33}$; y como criterios básicos para su análisis se fijan que la diferencia por edad responda a un elemento esencial, determinante, legítimo y proporcional. Y la conclusión que se puede obtener es clara: deben revisarse todas aquellas ofertas de empleo -privados o públicos- en los que se limita el acceso por razón de la edad, sin una debida justificación para seleccionar al personal. Baste pensar en los anuncios para diversos colectivos que se pueden leer en distintos sitios, para hostelería, relaciones sociales, talleres, etc., donde se restringe la edad de los candidatos; agrupaciones profesionales que segmentan los colectivos por edades; doble escala salarial basada en la edad, agencias de colocación que no mueven las solicitudes de determinada edad; medidas de fomento del empleo que se fijan en una determinada capa de edad, o flexibilidad interna o externa que protege sólo a los mayores,..., que exigirían una revisión sobre las condiciones en las que se aplican o, cuando menos, una justificación más fundamentada para su aceptación ${ }^{34}$.

No obstante, no ha sido éste un pronunciamiento novedoso, dado que ha habido otras tres ocasiones anteriores donde se ha examinado el mismo problema; y así, se podrían citar la Sentencia del Tribunal de Justicia de la Unión Europea de 13 de noviembre de 2014, asunto Vital Pérez, en el que se cuestionaba la fijación de un tope de edad, treinta años, para acceder a un puesto de Policía Local de Oviedo, y se consideró que la medida era desproporcionada para lograr el objetivo perseguido. La Sentencia del Tribunal de Justicia de la Unión Europea de 13 de septiembre de 2011, asunto Priggey, referida a un

\footnotetext{
${ }^{32}$ Apartado 48.

${ }^{33}$ Apartado 47.

${ }^{34}$ Cfr. SEMPERE NAVARRO, A. V., «La edad para trabajar (al hilo del caso de la Policía Local de Oviedo)», en Actualidad Jurídica, núm. 897, 2015, consultado a través de la base de datos Westlaw (BIB 2015/24).
} 
piloto de Lufthansa que planteaba un contencioso contra su empleadora, por mor de su convenio colectivo, en el que se establecía una cláusula de extinción automática de la relación laboral a los sesenta años, a pesar de que las normativas nacional e internacional fijaban dicha edad en cinco años más, a los sesenta y cinco; y nuevamente se consideró que dicha normativa se oponía a la Directiva 2000/78/CE del Consejo, de 27 de noviembre de 2000 , porque esa jubilación obligatoria y distinta para los pilotos no es una medida necesaria para la seguridad pública y la protección de la salud y, además, la seguridad aérea no constituye un objetivo legítimo en el sentido del artículo 6 de la Directiva. Y, finalmente, la Sentencia Tribunal de Justicia de la Unión Europea de 12 de enero de 2010, asunto Wolf, que sí considera justificado el establecimiento de una edad máxima -treinta años- para la contratación de funcionarios en el servicio de bomberos, puesto que entiende que en este caso concurre un requisito «profesional esencial y determinante», que se residencia en el carácter operativo y el buen funcionamiento del servicio de bomberos profesionales, que el mismo argumento empleado para la Sentencia sobre la Ertzaintza.

En España, concretamente, la Sentencia del Tribunal Supremo de 5 de abril de 2017 Recurso de Casación núm. 1709/2015- de la Sala de lo contencioso-administrativo, ha considerado válida la fijación de un límite de treinta años para el acceso a los centros docentes de formación para la incorporación a la Escala de Cabos y Guardias; en suma, se afirma que la justificación es «la que descansa en las necesidades de un instituto armado de naturaleza militar de proveer sus distintos puestos de responsabilidad por miembros del mismo que hayan ido adquiriendo dentro del mismo la capacitación necesaria y la consiguiente necesidad de que el acceso al cuerpo se haga a una edad que permita alcanzar ese objetivo antes de que llegue la edad de retiro». Ratificando con ello el criterio establecido en la precedente Sentencia del Tribunal Supremo de 28 de enero de 2016 -Recurso de Casación núm. 480/2014-, referida a la fijación de límites de edad para el acceso a las Fuerzas Armadas.

\section{El cálculo de los umbrales de los despidos colectivos}

11. Sobre el particular se ha producido dos pronunciamientos las Sentencias del Tribunal de Justicia de la Unión Europea de 13 de mayo de 2015, asunto Rabal Cañas, C- 392/13, y de 11 de noviembre de 2015, asunto Pujante Rivera, C-422-14, que viene a clarificar la anterior en algunos aspectos. Ambas han tenido una gran importancia y, por ello, la recojo a los efectos de hacer un elenco de resoluciones relevantes. En resumen, han venido a ofrecer una solución hermenéutica desde el derecho comunitario a la expresión «empresa» empleada por el artículo 51.1 del Estatuto de los Trabajadores ${ }^{35}$, porque la opción legislativa por aquélla como unidad de cómputo no supone que se elimine totalmente la posibilidad de acudir a centro de trabajo -más restringido-, como tal unidad de cómputo, puesto que ésta está garantizada por la Directiva 98/59/CE, del Consejo, de 20 de julio de 1998, de tal forma que el legislador nacional, en este caso el

\footnotetext{
35 «1. A efectos de lo dispuesto en esta ley se entenderá por despido colectivo la extinción de contratos de trabajo fundada en causas económicas, técnicas, organizativas o de producción cuando, en un periodo de noventa días, la extinción afecte al menos a: a) Diez trabajadores, en las empresas que ocupen menos de cien trabajadores. b) El diez por ciento del número de trabajadores de la empresa en aquellas que ocupen entre cien y trescientos trabajadores. c) Treinta trabajadores en las empresas que ocupen más de trescientos trabajadores» (art. 51.1 ET).
} 
español, podría añadir otra unidad de cómputo, pero exclusivamente como garantía adicional y nunca como alternativa excluyente. Por lo tanto, como la legislación española sólo ha utilizado una única unidad de referencia (la empresa), sin dar cabida al otro elemento (centro de trabajo), se infringe la mencionada Directiva.

Para definir el centro de trabajo se emplean dos parámetros: uno positivo y otro negativo. El parámetro negativo supone que «no resulta esencial que disponga de una dirección facultada para efectuar autónomamente despidos colectivos» ${ }^{36} \mathrm{y}$ «no debe estar dotada necesariamente de autonomía jurídica alguna ni de una autonomía económica, financiera, administrativa o tecnológica para poder ser calificada de "centro de trabajo"» ${ }^{37}$. El positivo, supone tomar en consideración tres características más o menos definitorios: una, ha de tratarse de una «entidad diferenciada», lo que presupone encontrarse «adscrita a la ejecución de una o varias tareas determinadas», contando para ello con «un conjunto de trabajadores» y con «medios técnicos y un grado de estructura organizativa que le permita llevar a cabo esas tareas» ${ }^{38}$. Otra, debe tener «cierta permanencia y estabilidad» ${ }^{39}$, lo que tampoco se define ni explicita más allá de su enumeración. Y finalmente, la idea más elaborada, pues se relaciona con «las consecuencias socioeconómicas que los despidos colectivos podrían provocar en un contexto local y en un medio social determinados» ${ }^{40}$ : este rasgo parece matizar lo mantenido anteriormente por el Tribunal, pues en la Sentencia del Tribunal de Justicia de la Unión Europea de 15 de febrero de 2015, asunto Chartopoiïa, C-270/05, se decía que no «es preciso que exista una separación geográfica entre ella y otras unidades e instalaciones de la empresa» ${ }^{4}$.

La clarificación introducida por la segunda resolución se refiere, por una parte, al cómputo de los trabajadores con contrato temporal por obra o servicio determinado, puesto que éstos no podrán excluirse cuando sean trabajadores «habitualmente» empleados en el centro de trabajo; por otra parte, que para acreditar el despido colectivo conforme a la citada Directiva, que en su artículo 1.1.1.a) habla de que los «despidos sean al menos 5»-regla repetida en el artículo 51.1, apartado octavo del Estatuto de los Trabajadores $^{42}$ - se refiere a despidos en sentido estricto y no a otro tipo de extinciones asimiladas a los despidos; y, finalmente, que las medidas de flexibilidad interna, modificaciones colectivas, por motivos no inherentes a la persona del trabajador se asimilan a despido en sentido estricto, es decir, que la figura del despido engloba cualquier extinción que no haya sido deseada por el trabajador ${ }^{43}$.

\footnotetext{
${ }^{36}$ Apartado 44.

${ }^{37}$ Apartado 47.

${ }^{38}$ Apartado 45.

${ }^{39}$ Apartado 45.

${ }^{40}$ Apartado 47.

${ }^{41}$ Apartado 29.

42 «Para el cómputo del número de extinciones de contratos a que se refiere el párrafo primero de este apartado, se tendrán en cuenta asimismo cualesquiera otras producidas en el periodo de referencia por iniciativa del empresario en virtud de otros motivos no inherentes a la persona del trabajador distintos de los previstos en el artículo 49.1.c), siempre que su número sea, al menos, de cinco» (art. 51.1, ap. 8 ET).

${ }^{43}$ Para un análisis más extenso, puede consultarse GARCÍA-PERROTE ESCARTÍN, I., «De nuevo sobre las extinciones que deben computarse en el despido colectivo y los plurales criterios del tribunal de justicia de la Unión Europea», en Revista de Información Laboral, núm. 12, 2015, consultada a través de la base de datos Westlaw (BIB 2015/18180).
} 


\section{El uso de velo islámico en el lugar de trabajo}

12. El uso del velo islámico en el trabajo -en cualquiera de sus modalidades, chador, niqab, hiyab o burka- es bastante controvertido y sobre el asunto se podría mencionar la reciente Sentencia del Tribunal de Justicia de la Unión Europea de 14 de marzo de 2017, asunto Achbita, C-157/2015, en el que se analiza la prohibición a una trabajadora de religión musulmana llevar velo en el trabajo y, ante su negativa a cumplir dicha orden, despedirla; de lo que se trata es de resolver un problema que presenta una gran conflictividad social, exacerbado por los últimos y luctuosos acontecimientos producidos en Europa, desde el prisma del principio de no discriminación por motivos de religión o convicciones. El supuesto de hecho es sencillo -relativamente-, se trataba de una empresa de seguridad en la que trabajaba la actora y en la que está prohibido, al menos inicialmente de manera no escrita, portar símbolos religiosos, políticos o filosóficos en el trabajo; la Sra. Achbita trabajaba de recepcionista y ya profesaba la religión musulmana cuando comenzó a trabajar, aunque utilizaba el pañuelo islámico fuera del horario de trabajo; en un momento determinado decide empezar a utilizarlo durante su jornada laboral. La empresa le prohíbe ponerse el centro del trabajo y, ante su negativa a dejar de ponérselo, la despide y la indemniza.

La decisión del tribunal comunitario descarta la existencia de discriminación directa por el mero hecho de la prohibición, en el sentido del artículo 2, apartado 2, letra a), de la Directiva 2000/78/CE siembre que dicha prohibición se base en una norma general de empresa dirigida a prohibir el uso de símbolos visibles políticos, filosóficos y religiosos en el trabajo y no se base en estereotipos o prejuicios contra una o varias religiones concretas ni contra las creencias religiosas en general; y, en lo que respecta a la posible existencia de una discriminación indirecta, podría entrañarla si se acredita que la obligación aparentemente neutra que contiene ocasiona, de hecho, una desventaja particular a aquellas personas que profesan una religión o tienen unas convicciones determinadas, salvo que pueda justificarse objetivamente con una finalidad legítima, como el seguimiento por parte del empresario de un régimen de neutralidad política, filosófica y religiosa en las relaciones con sus clientes, y que los medios para la consecución de esta finalidad sean adecuados y necesarios, extremos que corresponderá comprobar al tribunal remitente ${ }^{44}$. En definitiva, se ha concluido por el Tribunal que los deseos de un cliente de que los servicios de dicho empresario no sigan siendo prestados por una trabajadora que lleva un pañuelo islámico constituye un requisito profesional esencial y determinante en el sentido de la citada disposición.

13. El tema es -desde luego- espinoso ${ }^{45}$ y, probablemente, no sea la última decisión que se adopte sobre el mismo, pudiendo destacarse una decisión en sentido diverso en la Sentencia del Juzgado de lo Social núm. Uno de Palma de Mallorca de 6 de febrero de 2017 -Procedimiento núm. 478/2016-, en la que se daba la razón a una trabajadora que demando a su empresa por prohibirle el empleo del velo islámico, aquélla presta servicios en el departamento de servicio al pasajero y, por tanto, de cara al público, habiendo solicitado hacer uso del velo islámico como expresión de su sentimiento

\footnotetext{
${ }_{45}^{44}$ Apartado 44.

${ }^{45}$ Cfr. NIETO ROJAS, P., «Libertad religiosa y negociación colectiva. Su especial incidencia en la fijación de los descansos laborales», en Revista de Información Laboral, núm. 4, 2017, consultada a través de la base de datos Westlaw (BIB 2017/11077).
} 
religioso, lo que inicialmente le fue autorizado por la empresa de forma provisional y, después, negado bajo la invocación de las exigencias de uniformidad y la imagen corporativa de la empresa para justificar dicha negativa. La sentencia termina concluyendo que la compañía ha vulnerado el derecho fundamental a la libertad religiosa y le ordena permitir su uso, mientras desempeñe sus funciones como azafata de tierra, amén de una indemnización adicional; porque -se argumenta- que «[1]a empresa no ha invocado una política de neutralidad religiosa, ni cualquier otro motivo que tuviera que ver con el modo de expresión de la creencia religiosa de la trabajadora o con la seguridad, alega simplemente que sus empleados en el departamento de atención al pasajero deben cumplir las normas de uniformidad que no permiten hacer uso de prendas o elementos distintos de los que ella misma proporciona, en defensa de una buena imagen corporativa; No ha invocado ni concretado, como ya se ha apuntado, perjuicio alguno».

\section{La maternidad}

14. En este aspecto han sido varios los pronunciamientos recientes que pueden interesar, una sería la Sentencia Tribunal de Justicia de la Unión Europea de 16 de julio de 2015, asunto Maïstrellis, C-222/14, en el que se abordaba la conformidad de la normativa griega respecto del Acuerdo marco sobre el permiso parental celebrado por la UNICE, el CEEP y la CES (la Directiva 96/34/CE), puesto que en ella se privaba del derecho al permiso parental al funcionario cuya esposa no trabaja, salvo que, debido a dolencia o enfermedad grave, se la considere incapacitada para hacer frente a las necesidades de cuidado del hijo. Lo que también se produce en España, en casos recientes, que todavía no tienen una solución judicial firme, y referidos a miembros de la Carrera Judicial cuyas parejas o esposas no prestan servicios o están incluidas en regímenes en los que no se reconoce la maternidad (por ejemplo, la Mutualidad de la Abogacía).

Otro, tiene que ver con la últimamente mediática maternidad subrogada, debido a la Sentencia del Tribunal Supremo, que ha venido a alterar -en cierta medida- el criterio que se había mantenido por el Tribunal de Justicia de la Unión Europea sobre la cuestión, porque la Sentencia del Tribunal Supremo de 25 de octubre de 2016 -Recurso de Casación para la unificación de doctrina núm. 3818/2015- ${ }^{46}$ ha reconocido las prestaciones de maternidad a un trabajador que ha sido padre biológico, a través de un contrato de gestación por sustitución y cuyas hijas constan inscritas en el Registro Civil del Consulado de España en Nueva Delhi. En suma, se considera que el Convenio Europeo de Derechos Humanos ampara el derecho a la inscripción de menores nacidos tras gestación por sustitución en ciertos casos, aunque no condiciona el derecho a la protección social (a prestaciones de Seguridad Social), porque se reitera el criterio de la Sala Primera que entiende que las normas civiles españolas, que declaran nulo el contrato de maternidad por subrogación, impiden que pueda inscribirse como hijos de quienes han recurrido a esa técnica los habidos en un tercer Estado, no obstante, para el caso de que los menores posean relaciones familiares o exista una verdadera integración en el núcleo familiar se debe permitir el desarrollo y su protección. El mismo sentido se

\footnotetext{
${ }^{46}$ Cfr. ARAGÓN GÓMEZ, C., «La legalización de facto de la maternidad subrogada. A propósito de los recientes pronunciamientos de la sala de lo social del tribunal supremo con respecto a las prestaciones por maternidad», en Revista de Información Laboral, núm. 4, 2017, consultada a través de la base de datos Westlaw (BIB 2017/11072).
} 
había consolidó en la posterior Sentencia del Tribunal Supremo de 16 de noviembre de 2016 - Recurso de Casación para la unificación de doctrina núm. 3146/2014-, en la que una trabajadora solicita la prestación por maternidad al tener a su hijo en virtud de un contrato de gestación por sustitución, e inscrito en el Registro del Consultado de España en Los Ángeles, figurando la actora como madre y su pareja varón como padre. «El Alto Tribunal en ambos casos concede las prestaciones por maternidad, en base a la especial protección y supremacía en interés del menor no pudiendo mermar ni perjudicar sus derechos la nulidad del contrato de gestación o vientre de alquiler, así como la prohibición de inscribir a los niños en el registro. Ambos, son temas que deben quedar al margen primando la atención del menor» ${ }^{47}$.

Sin embargo, esta línea parece contradecir la posición mostrada por el alto tribunal comunitario, en distintas ocasiones. En la Sentencia del Tribunal de Justicia de la Unión Europea de 18 de marzo de 2014, C-167/12, se aborda el problema derivado de una normativa nacional (en concreto, del Reino Unido), que deniega el permiso de maternidad a una trabajadora, en su calidad de madre subrogante, pues ha tenido un hijo gracias a un convenio de gestación por sustitución, a pesar de que pueda amamantar a ese niño tras su nacimiento o lo amamanta efectivamente; o, en la Sentencia del Tribunal de Justicia de la Unión Europea de 18 de marzo de 2014, C-363/12, referida una empleada de Irlanda que solicita la prestación por maternidad subrogada, tratándose de una institución desconocida en el ordenamiento de ese país, y en la que el Tribunal considera que es válida la exclusión de prestaciones por la normativa nacional, concluyendo que «no constituye una discriminación basada en el sexo el hecho de denegar la concesión de un permiso retribuido equivalente al permiso de maternidad a una trabajadora, en su calidad de madre subrogante que ha tenido un hijo gracias a un convenio de gestación por sustitución. La situación de una madre subrogante en lo concerniente a la atribución de un permiso por adopción no está comprendida en esta Directiva» [Directiva 2006/54/CE del Parlamento Europeo y del Consejo, de 5 de julio de 2006, relativa a la aplicación del principio de igualdad de oportunidades e igualdad de trato entre hombres y mujeres en asuntos de empleo y ocupación].

\section{El acceso a un puesto de trabajo sólo para solicitar una indemnización por discriminación}

15. Una última referencia a la jurisprudencia del Tribunal sería la Sentencia del Tribunal de Justicia de la Unión Europea de 28 de julio de 2016, asunto Kratzer, C-423/15, en la que se analiza un curioso thema: la presentación de una candidatura a un empleo para obtener la condición formal de candidato con el único fin de pedir una indemnización por discriminación. Se trataría de un candidato a una oferta de empleo, cuya presentación no se produce para obtener el puesto de trabajo, sino sólo para, una vez rechazado por su edad -en el caso que se examinaba-, ejercitar acciones resarcitorias contra el empresa por discriminarlo. La conclusión del Tribunal es clara: «[e]l artículo 3, apartado 1, letra a), de la Directiva 2000/78/CE del Consejo, de 27 de noviembre de 2000, relativa al establecimiento de un marco general para la igualdad de trato en el empleo y la ocupación, y el artículo 14, apartado 1, letra a), de la Directiva 2006/54/CE

\footnotetext{
${ }^{47}$ Para análisis más profundo del tema, véase INDA ERREA, M., «Los padres de «vientres de alquiler» podrán acogerse a la baja maternal», en Revista Aranzadi, núm. 7, 2017, consultado a través de la base de datos Westlaw (BIB 2017\10626).
} 
del Parlamento Europeo y del Consejo, de 5 de julio de 2006, relativa a la aplicación del principio de igualdad de oportunidades e igualdad de trato entre hombres y mujeres en asuntos de empleo y ocupación, deben interpretarse en el sentido de que una situación en la que una persona que, presentando su candidatura a un empleo, no pretende obtener dicho empleo, sino sólo la condición formal de candidato con el único propósito de reclamar una indemnización, no está comprendida en el concepto de "acceso al empleo o a la ocupación" en el sentido de tales disposiciones y puede ser calificada de abuso de derecho si concurren los elementos exigidos con arreglo al Derecho de la Unión».

\section{CONCLUSIONES}

16. La jurisprudencia del Tribunal de Justicia de la Unión Europea cada día tiene mayor relevancia práctica, muchas de las construcciones elaboradas por los tribunales españoles en base a nuestra normativa se han visto alteradas de manera drástica, no sólo en cuanto a cómo se calcula el número de trabajadores afectados por un despido colectivo, o la necesaria equiparación de los trabajadores interinos a los indefinidos, sino también las limitaciones derivadas de la edad -discriminación- o el uso del velo islámico en el puesto de trabajo. Es, por ello, que el estudio y difusión de la doctrina de este órgano judicial adquiera tintes esenciales y deba hacerse hincapié en sus distintos pronunciamientos, de tal forma que su trascendencia sólo se advertirá pasado el tiempo y una vez que la jurisprudencia nacional se adapte debidamente a aquélla, pese a los impedimentos que puedan surgir. Lo que se ha visto reflejado en los tres puntales, a lo que se hacía referencia al comienzo del artículo: su aplicación directa, aunque sólo en las relaciones verticales y muy dudosamente en las horizontales (esto es, en las relaciones entre particulares); su reconocimiento legal expreso, pues puede ser base para interponer el recurso de casación para la unificación de doctrina (artículo 219.2 de la Ley Reguladora de la Jurisdicción Social); y su consideración como «jurisprudencia» a los efectos del artículo 193.c) de la Ley Reguladora de la Jurisdicción Social. En definitiva, es preciso el estudio y actualización constante a las decisiones del órgano judicial comunitario, en la medida en que van a conformar la interpretación y las líneas maestras de importantes instituciones españolas.

\section{BIBLIOGRAFÍA}

ARAGÓN GÓMEZ, C., «La legalización de facto de la maternidad subrogada. A propósito de los recientes pronunciamientos de la sala de lo social del tribunal supremo con respecto a las prestaciones por maternidad», en Revista de Información Laboral, núm. 4, 2017

CANTO GARCÍA, M., «El efecto directo horizontal en las directivas y el Tratado de Maastricht», en Boletín de Información. Ministerio de Justicia e Interior, núm. 1730-31, 1995

CONSEJO GENERAL DEL PODER JUDICIAL, Panorámica de la Justicia 
DE CASTRO MEJUTO, L. F, «La prestación de maternidad por adopción en supuestos de previa convivencia», en Anuario de la Interdisciplinar Facultad de Derecho de la Universidad de A Coruña. Revista Jurídica Internacional, Volumen XV (2011)

DESDENTADO BONETE, A., «¿Un miércoles de ceniza para la contratación temporal española? Reflexión breve sobre la sentencia del Tribunal de Justicia de la Unión Europea en el caso de Diego Porras», en Revista de Información Laboral, núm. 10, 2016

DESDENTADO DAROCA, E., «El despido del enfermo y la STJUE de 1 de diciembre de 2016 dictada en el caso Daouidi. Algunas reflexiones críticas», en Revista de Información Laboral, núm. 3, 2017

GARCÍA-PERROTE ESCARTÍN, I., «De nuevo sobre las extinciones que deben computarse en el despido colectivo y los plurales criterios del tribunal de justicia de la Unión Europea», en Revista de Información Laboral, núm. 12, 2015

INDA ERREA, M., «Los padres de "vientres de alquiler" podrán acogerse a la baja maternal», en Revista Aranzadi, núm. 7, 2017

LÓPEZ BALAGUER, M., «La aplicación de la doctrina «De Diego Porras» al contrato para obra o servicio determinado en el ámbito privado. STSJ País Vasco, de 18 de octubre de 2016 (AS 2016, 1446)», en Revista Española de Derecho del Trabajo, núm. 195,2017

MARTÍNEZ GIRÓN, J., ARUFE VARELA, A. y CARRIL VÁZQUEZ, X. M., Derecho del Trabajo, $2^{\text {a }}$ edición, Netbiblo (A Coruña, 2006)

MILLÁN MORO, L., «La eficacia directa de las directivas: evolución reciente», en Revista de Instituciones Europeas, volumen 18, núm. 3, 1991

NIETO ROJAS, P., «Libertad religiosa y negociación colectiva. Su especial incidencia en la fijación de los descansos laborales», en Revista de Información Laboral, núm. 4, 2017

PANEA HERNANDO, D. J., «Nuevas sentencias a raíz del asunto "De Diego Porras”», en Centro de Estudios Financieros, accesible en http://www.laboral-social.com/nuevassentencias-asunto-diego-porras.html.

RODRÍGUEZ CRESPO, M. J., «Límites al uso abusivo de la contratación temporal por parte de las Administraciones Públicas. Un análisis a la luz de los recientes pronunciamientos del TJUE: asuntos María Elena López contra el Servicio Madrileño de Salud y Martínez Andrés (C-16/15) y Otro contra el Servicio Vasco de Salud (C184/15)», en Revista de Información Laboral, núm. 4, 2017

SÁNCHEZ PÉREZ, J., «El despido del trabajador en situación de incapacidad temporal: el derecho al rendimiento empresarial frente al derecho de protección de la salud», en Revista de Información Laboral, núm. 5, 2017 
SEMPERE NAVARRO, A. V., «La edad para trabajar (al hilo del caso de la Policía Local de Oviedo)», en Actualidad Jurídica, núm. 897, 2015 